\title{
Renewable Energy in Islands. An Integrated Proposal for Electricity Generation and Transports
}

\author{
P. Marques ${ }^{1}$, E. Silva ${ }^{1}$, C. Camus ${ }^{1}$ and E. Eusébio ${ }^{1}$ \\ ${ }^{1}$ Department of Power Systems Engineering and Automation \\ ISEL, Instituto Politécnico de Lisboa \\ Rua Conselheiro Emídio Navarro nº 1, 1959-007 Lisboa (Portugal) \\ Phone: +351218317000, e-mail: 32936@ alunos.isel.pt, 33199@alunos.isel.pt, ccamus@ deea.isel.ipl.pt, \\ eaeusebio@deea.isel.ipl.pt
}

\begin{abstract}
The purpose of this article is to analyse and evaluate the economical, energetic and environmental impacts of the increasing penetration of renewable energies and electrical vehicles in isolated systems, such as Terceira Island in Azores and Madeira Island.

Given the fact that the islands are extremely dependent on the importation of fossil fuels - not only for the production of energy, but also for the transportation's sector - it's intended to analyse how it is possible to reduce that dependency and determine the resultant reduction of pollutant gas emissions.

Different settings have been analysed - with and without the penetration of EVs. The Terceira Island is an interesting case study, where EVs charging during off-peak hours could allow an increase in geothermal power, limited by the valley of power demand. The percentage of renewable energy in the electric power mix could reach the $74 \%$ in 2030 while at the same time, it is possible to reduce the emissions of pollutant gases in $45 \%$ and the purchase of fossil fuels in 44\%. In Madeira, apart from wind, solar and small hydro power, there are not so many endogenous resources and the Island's emission factor cannot be so reduced as in Terceira. Although, it is possible to reduce fossil fuels imports and emissions in $1.8 \%$ in 2030 when compared with a BAU scenario with a $14 \%$ of the LD fleet composed by EVs.
\end{abstract}

\section{Key words}

Renewable energy, Electric vehicles, Madeira Island, Terceira Island, Load profile.

\section{Introduction}

Energy is basic to life, to the citizens' well being and to the social and economical development, that is, without energy there can only be so much quality of life: comfort, property and services. However, besides being an essential resource to the social and economical development, energy is also a strong factor of environment pressure [1].

As far as the energy's production is concerned, most islands depend on the importation of oil and its related products, expensive and highly problematic to the environment.

In most cases it's almost impossible to connect the islands to the energy network in continental Europe, which makes it difficult to execute solutions to reduce the costs to the environment and, at the same time, increase the security of the supply of electrical energy in order to maintain the quality of life and the islands economical structures and sustainability. Due to the high costs of energy, the islands are proven to be excellent test points for the introduction of new technologies, and some islands are even trying to become, the so called, renewable islands in order to satisfy the demand of totally renewable energy, or at least, energies that are mostly originated from renewable and endogenous resources, which rises the security of the supply and employment opportunities, without necessarily rising costs. Islands that have renewable energy sources, such as hydro-electric and geothermic, can easily integrate them in the energy's system [2]. However, the energy provided by renewable sources, like the wind and the sun, aren't constant and are rarely predictable. Those fluctuations in the energy's supply can cause differences in the necessary balance between production and demand. As consequence, important variations on the frequency and tension levels are verified, which may affect the electrical energy's system stability. These problems are serious in small isolated networks, therefore, it's necessary to continuously control the instant power supplied by renewable energies' sources [3].

On the islands, because they're smaller and less busy territories, the incentive to the use of public transportations is very narrow (because private transportations don't face the main two big issues known in cities: the time of travel and the difficulty to park). Given this fact, it's imperative to turn the private fleets electrical, more than implement intensive measures to promote public transportations [4].

\section{Isolated System Analysis}

The integration of renewable energies on the islands' energy system presents several advantages, including on the economical level: the technological high cost is compensated by the high cost of the conventional energy sources due to the small dimension of the systems and the supply security. In order to obtain a sustainable development, the integration of renewable energy sources to produce electricity as well as the policies and 
appropriate regulations about the rational use of energy are very important.

The conventional technologies to produce electricity are rarely adapted to the conditions of isolated areas and may seriously damage the vulnerable ecosystems and natural habitats. There is the need to develop an infrastructure to supply energy which considers the seasonal variations caused by the tourism, without destroying the local environment or produce unnecessary emissions [5].

\section{A. Canary Islands (Spain)}

The political and environmental concerns result in a special energetic strategy in Canary Islands, which shows the importance of improving the endogenous energetic resources and the renewable energies, in order to provide energy for a constant and stable supply, low cost and environmental compatible. Here, the wind and solar energy have been reinforced and the solar panels and photovoltaic systems expanded. Previous studies show that an isolated system of energy storage is extremely important for the use of a huge potential of wind energy on the islands [6].

\section{B. Arø Island (Denmark)}

The solar energy is used for urban heating, being this the main energy source in Aero Island.

Nowadays, the thermal solar panels installed are 39,83 square feet $\left(3,7 \mathrm{~m}^{2}\right)$ per inhabitant in a total of 288472,79 square feet $\left(26800 \mathrm{~m}^{2}\right)$; there are three power plants of urban heating on the island, which result in the most developed penetration of renewable energy in a specific area.

In 2001 it was estimated that $20.5 \mathrm{GWh}$, illustrating $57 \%$ of the total electricity consumption in Aero was supported by 7.2 MW of wind energy.

It was decided, in Aero, to work continuously to cover the energy's consumption on the islands with 80 to $100 \%$ of renewable energy during the period of 10 years (19982008). In 2000, Aero Island was the winner of "Danish Solar City”. [6] [7].

\section{Greek Islands}

Several types of renewable energies are used on the Greek Islands. By 2005, 50 wind parks were installed with the total of $120 \mathrm{MW}$ and $300 \mathrm{KWp}$ of photovoltaic energy yet to finalize its installation. Besides, a small hydroelectric unit $(300 \mathrm{~kW})$ and a unit of gas flaring $(166 \mathrm{~kW})$ are situated in Crete. On Ikaria Island an hybrid energy system includes a regular hydroelectric unit - connected to two pumping-and-storing plants of $3.8 \mathrm{MW} \mathrm{-} \mathrm{and} \mathrm{a} \mathrm{wind}$ park of 2.4 MW. In 2003, the electrical system produced $23 \mathrm{GWh}$ of energy, $6.23 \mathrm{GWh}(27.1 \%)$ of which was wind energy, $7.96 \mathrm{GWh}(34.6 \%)$ and $8.80 \mathrm{GWh}$ (38.3\%) were supplied by fossil fuels and hydroelectric prospectively [6].

\section{Corvo Island (Azores)}

Corvo is the smallest island of Azores archipelago and the supply of electrical energy for such small and isolated island is extremely limited. There is also a huge concern about environment issues related to the fossil fuel, for example, the contamination and pollution of the water and soil by oil related products that happen through the leaking of such materials during the transportation and storage. The fuel costs for Corvo Island is the highest of the entire archipelago - almost five times over the average of other islands.

Here, the security of the supply is a real and permanent concern because, due to the unstable weather conditions, it's common for oil to lack. To reduce Corvos's dependency and facilitate a secure supply, the implementation of an energy system that combines renewable energy systems and oil supply is the best solution.

The most important endogenous resource in Corvo is the wind, although there is also some hydropower potential; both of them being deficient during the summer.

The water supply system is well prepared to integrate with the energy supply system's storage like the reversible hydroelectric. The same reservoir may be used for both, which increases the viability of such system, as well as the energy's penetration.

Because of the physical and weather characteristics of Corvo there is potential to install the storage of pumped water to produce hydroelectric energy later in time. The installation of turbines offers benefits of about $70 \%$; this is possible because the water from the top reservoir can be used to produce electricity, which will be supplied to the network and, then, fill the low reservoir.

Without storage, the penetration of renewable energy from the wind reaches 25\%; considering a windhydropower setting it's possible to supply up to $70 \%$ of energy from renewable sources, highly increasing security supply [8].

\section{E. Porto Santo Island (Madeira)}

An essay has been made about the increase of RE in Porto Santo. Since the island doesn't have hydro resources available, the endogenous resources are the sun and the wind. In order to increase the RE, it's necessary to resort to storage and that can be made by using hydrogen through electrolysis, kept in a fuel cell and used when necessary to supply the network with energy [9].

\section{Grid Characterization}

Islands are isolated systems unless they are sufficiently near the continent in order to be connected by cables along the sea bottom. The islands used in this study are isolated. In the next sub-sections there are a characterization of the electricity's systems of each of the islands in analysis.

\section{A. Terceira Island (Azores)}

The electricity system of Terceira includes six powerstations, as it shows on Table I.

Table I - Power-stations in 2012

\begin{tabular}{|c|c|c|}
\hline Designation & $\begin{array}{c}\text { Primary } \\
\text { source }\end{array}$ & $\begin{array}{c}\text { Installed } \\
\text { Power(kW) }\end{array}$ \\
\hline
\end{tabular}




\begin{tabular}{|c|c|c|}
\hline $\begin{array}{c}\text { Belo Jardim Thermal } \\
\text { Unit }\end{array}$ & Fueloil & 61116 \\
\hline City’s Hydric Unit & \multirow{2}{*}{ Hydro } & 264 \\
\cline { 1 - 1 } $\begin{array}{c}\text { Nasce D’Água Hydro } \\
\text { Unit }\end{array}$ & 720 \\
\cline { 1 - 1 } São João Hydro Unit & Wind & 448 \\
\hline $\begin{array}{c}\text { Serra do Cume Wind } \\
\text { Farm }\end{array}$ & 9000 \\
\hline $\begin{array}{c}\text { Serra do Cume North } \\
\text { Wind farm }\end{array}$ & - & 75148 \\
\hline Total & & 7500 \\
\hline
\end{tabular}

Between 1991 and 2010 it was confirmed a substantial increase of electrical energy (Fig. 1). It is also worthy of notice that when the wind farm of Serra do Cume began its activity, in 2008, the thermal power plant decreased its production because of the energy produced by the wind.

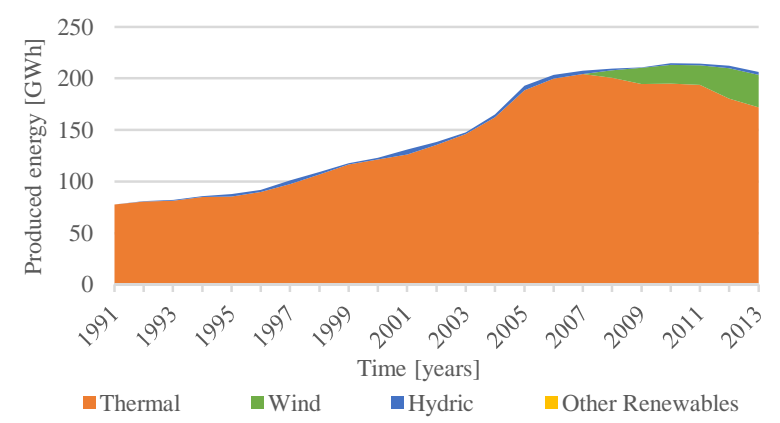

Fig. 1. The evolution in electrical energy according to the type

In 1991 all the electrical energy produced in Terceira was from fossil fuels. In 2013 there was a production of $17 \%$ originated on RE, $15 \%$ of which was wind energy (Fig. 2).

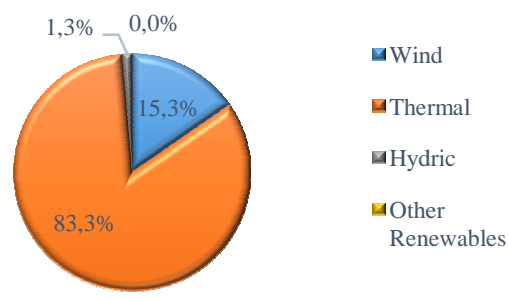

Fig. 2. Production of electrical energy in 2013

Fig. 3 represents the load diagram of a typical spring day. This diagram shows that there is a valley in the power consumption that represents $60-70 \%$ of the peak consumption. Terceira Island has a great potential of geothermal energy because it lays between two tectonic plates, the Eurasian and the African. There is a possibility of installing $12 \mathrm{MW}$ of geothermal power, which could increase the renewable generation to more than $50 \%$.

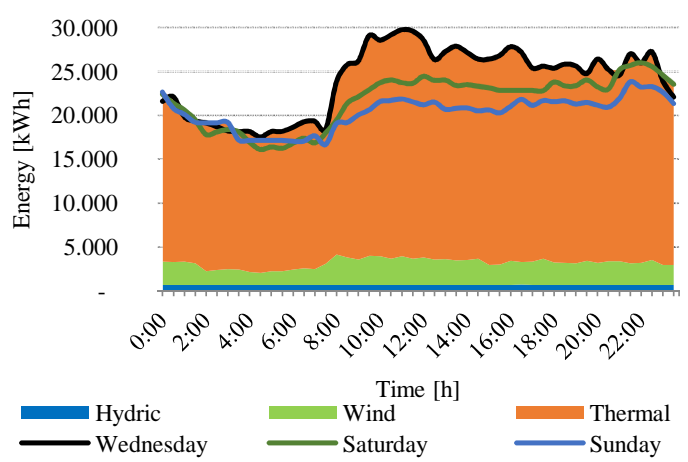

Fig. 3. Typical load profile on a spring day 2013

\section{B. Madeira Island}

The electricity generation system in Madeira Island includes two thermal power plants operating on fuel oil, ten hydroelectic stations, nine wind parks, one station of treatment of municipal solid waste (MSW) and seven hundred and nine photovoltaic panels. According to the data on Table II, we can analyse the installed power of each technology.

Table II - Electricity producing system in Madeira, 2013

\begin{tabular}{|c|c|}
\hline $\begin{array}{c}\text { Eletroproductor System of Empresa de Eletricidade } \\
\text { da Madeira (EEM) }\end{array}$ \\
\hline Technology & Installed Power [MW] \\
\hline Thermal & 182,70 \\
\hline Hydro & 49,97 \\
\hline Eletrogeneration System of Private Companies \\
\hline Technology & Installed Power [MW] \\
\hline Thermal & 36 \\
\hline Hydro & 0,7 \\
\hline Wind & 45,11 \\
\hline Photovoltaic & 17,96 \\
\hline MSW & 8 \\
\hline Total & 340,44 \\
\hline
\end{tabular}

The production of electrical energy in Madeira's network increased until 2008; after that year, the energy from thermal sources has decreased. On the contrary, the energies originated from renewable sources have increased (Fig. 4).

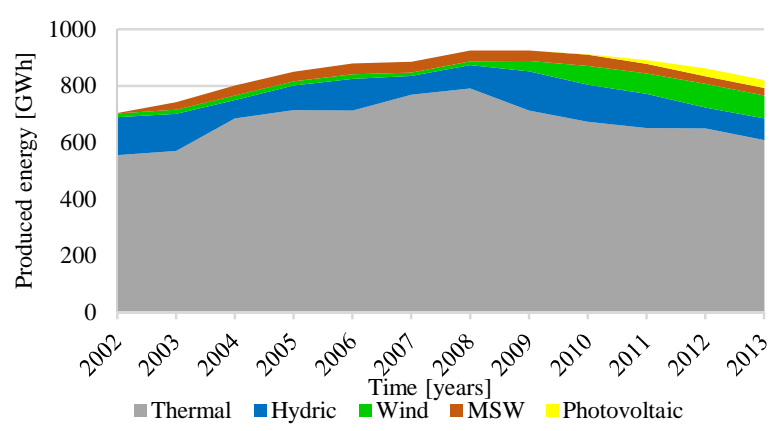

Fig. 4. Evolution on the production of electrical energy according to each type of technology

Fig. 5, represents the contribution of each technology for the electrical network in 2013. 


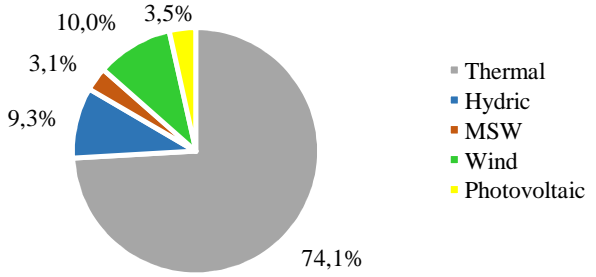

Fig. 5. Contribution of energy per source in 2013

Fig. 6 shows a diagram of average load in spring for the same year.

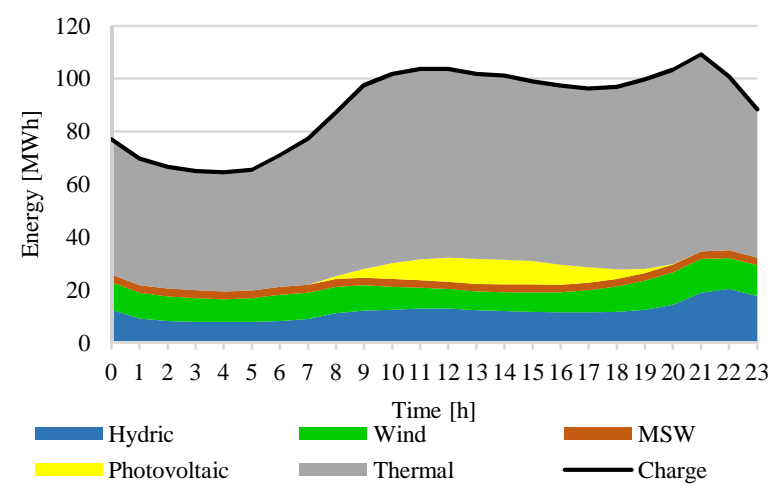

Fig. 6. Average load profile for spring 2013

\section{Methodology}

\subsection{Automotive sector}

In order to understand the evolution of the fleet of cars on the islands, firstly it was calculated the density of vehicles (number of vehicles per 1000 inhabitants), using the numbers of vehicles and the numbers of inhabitants of each island.

$$
f_{t}=\frac{N_{c_{t}} \times 1000}{H_{x_{t}}}
$$

With:

$f_{t}$ - Number of vehicles per 1000 inhabitants with real figures for year $\mathrm{t}$;

$N_{c_{t}}$ - Number of passenger's vehicles for year t;

$H_{x_{t}}$ - Number of inhabitants for location $x$ for year $\mathrm{t}$, with $x$ equal to Terceira or Madeira Island.

The equation used to estimate de vehicles' density was Gompertz function, which formula is expressed in (2) [10].

$$
V D_{t}=c+(S-c) \cdot e^{-e^{-b(t-a)}}
$$

\section{Considering:}

$V D_{t}-$ Density of vehicles for year $t$;

$S$ - Saturation point;

$a$ - Inflexion point of the time axis' curve;

$b$ - Parameter of scale;

$c$ - Translation on axis' curve of y;

$t$ - Time in years.

In order for the density curve of the vehicles to be well adjusted to the real figures, it was used the method of minimum squares with the following expression:

$$
\begin{gathered}
\min \sum_{\text {s. } a .}\left(f_{t}-V D_{t}\right)^{2} \\
b \geq 0 \\
b \geq 0 \\
c \geq 0 \\
S \geq 0
\end{gathered}
$$

To verify if the Gompertz formula is well adjusted to the density of the existent vehicles the determination coefficient $\left(\mathrm{R}^{2}\right)$ was calculated:

$$
R^{2}=\left(\frac{\sum\left(\left(f_{t}-\bar{f}\right) \cdot\left(V D_{t}-\overline{V D}\right)\right)}{\sqrt{\left(\sum\left(f_{t}-\bar{f}\right)^{2}\right) \cdot\left(\sum\left(V D_{t}-\overline{V D}\right)^{2}\right)}}\right)^{2}
$$

With:

$R^{2}$ - Determination coefficient;

$\bar{f}$ - Number of passenger's vehicles per 1000 inhabitants according to average real figures;

$\overline{V D}$ - Average vehicle density.

Three different settings of EV's penetration on the two islands were considered, as we can see in Fig. 7, but this paper has only analysed the reference scenarios.

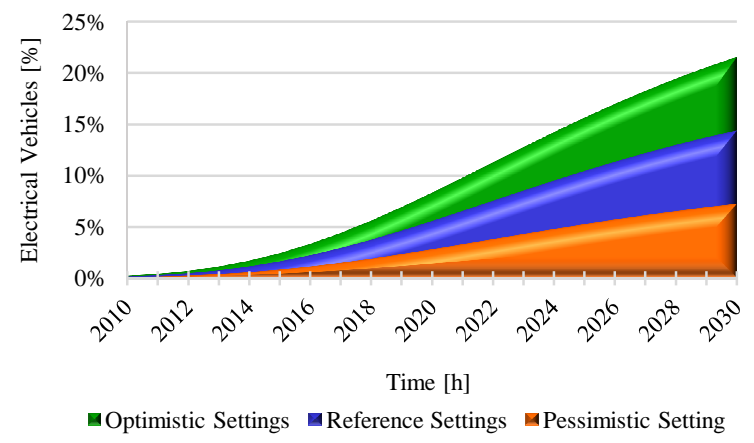

Fig. 7. Percentage of electrical vehicles for the optimistic, reference and pessimistic scenarios

The charging profiles of EVs considered were presented in Fig. 8 and 9. The off-peak charging for Madeira Island (considering a Gaussian distribution) and the controlled charging to Terceira with $14 \%$ EVs.

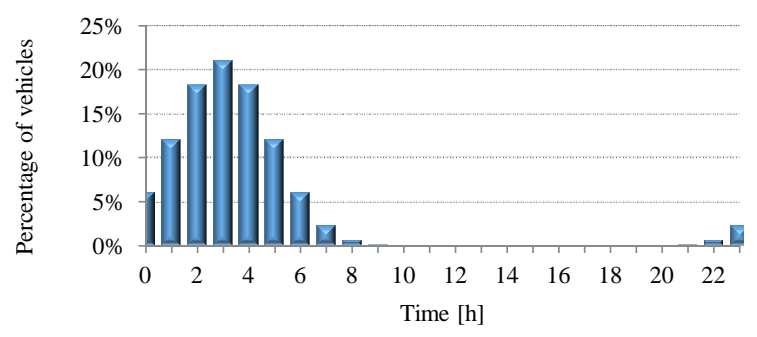

Fig. 8. Charging profile in off-peak 


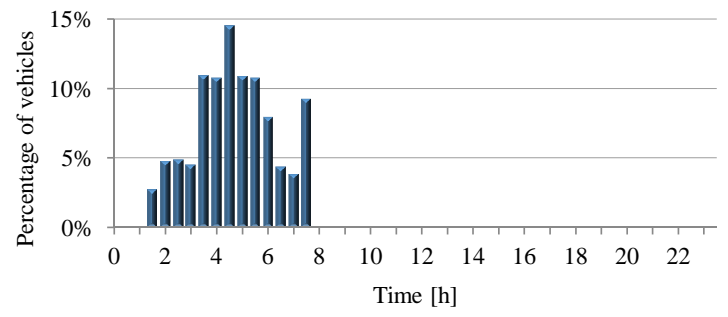

Fig. 9. Profile of charging controlled with $14 \%$ EV in spring

\subsection{Electrical sector}

To determine the evolution of electrical energy's consumption, it was used the same approach of calculus used in the evolution prediction in automobile sector, the Gompertz function, since the electrical energy's consumption presents a sigmoidal shape. This time, it was calculated the Consumption of Energy per capita (DC, Consumption Density, energy's consumption per each inhabitant resident in a certain country).

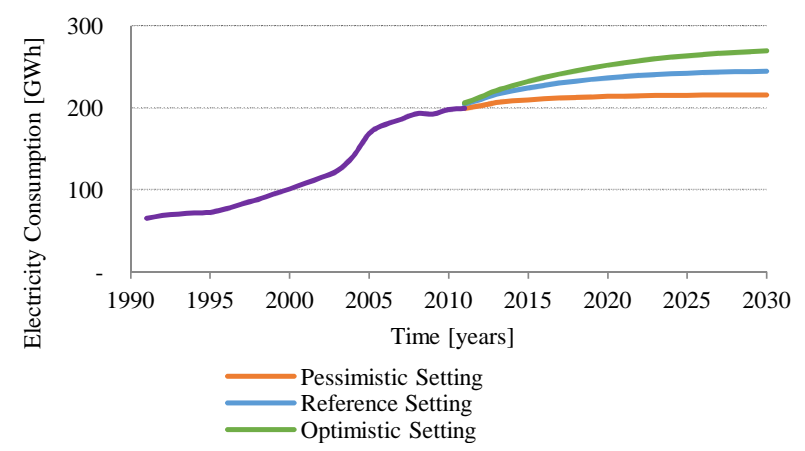

Fig. 10. Evolution and propensity of electricity's consumption in Terceira Island

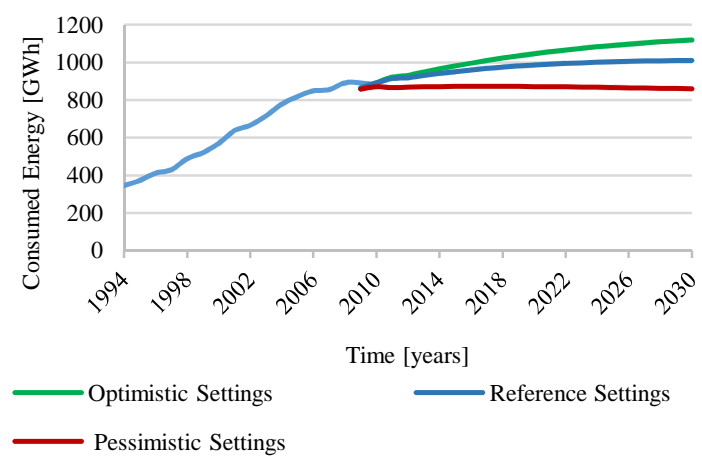

Fig. 11. Evolution and propensity of electricity's consumption in Madeira Island

\section{Case Study}

\section{A. Terceira Island (Azores)}

After analyzing the data on Table III (increase of capacity to install) and the $14 \%$ of EV's penetration with charging profile (Fig. 9), it was possible to obtain the graphic for 2030 (Fig. 12).

\begin{tabular}{|c|c|c|c|}
\hline Wind & Geothermal & Photovoltaic & Biomass \\
\hline $16,2 \mathrm{MW}$ & $12 \mathrm{MW}$ & $4,2 \mathrm{MW}$ & $3,07 \mathrm{MW}$ \\
\hline
\end{tabular}

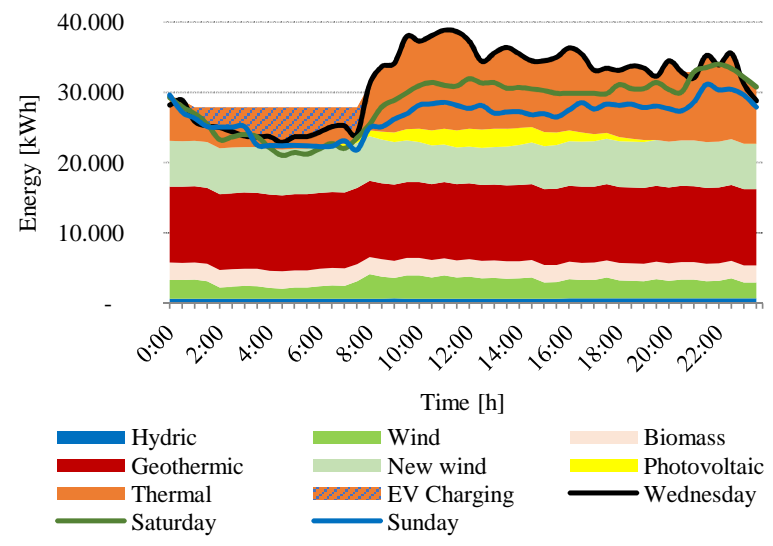

Fig. 12. Graphic of charge for 2030 with $14 \%$ of EVs

Comparing the previous data with the situation in 2030 it's quite clear, the thermal energy and that originated in fossil sources decrease considerably. The energy originated in renewable sources will increase from $17 \%$ in 2013 to $74 \%$ in 2030; this makes it possible to reduce the importation of fossil fuels in $44 \%$ and the emission of pollutant gases in $45 \%$. In conclusion, the use of renewable energy according to these figures allows the reduction of costs in the electrical sector by $11 \%$. Although it may not be forgotten that, in certain hours, if an increase in off-peak load is not achieved, the power system stability may be at risk. It is not possible to have the power system supplied only with uncontrollable renewable sources, there must be some controllable power plants to assure the balancing of the system.

EVs charging during off-peak hours could help in leveling the load profile and allowing the penetration of geothermal energy, a base load power source, renewable and without pollutant emissions and at the same time in those hours EVs could help in the balancing of the system if somehow the charging could be controlled by the power utility.

\section{B. Madeira Island}

The data on diagram for 2030 (Fig. 13) is the result of the data from Fig. 11 (which represents the setting of reference in the increase of charge), Table IV (which represents the increase of power to install) and Fig. 8 (which represents the penetration of $14 \% \mathrm{EV}$ with charging profile).

Table IV - Increase of power to install

\begin{tabular}{|c|c|}
\hline Wind & Photovoltaic \\
\hline $60 \mathrm{MW}$ & $20 \mathrm{MW}$ \\
\hline
\end{tabular}




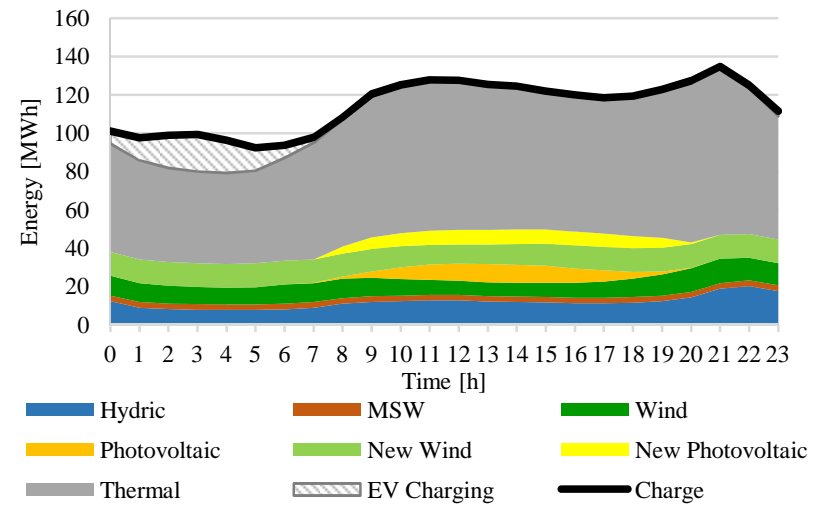

Fig. 15. Diagram of average charge for spring 2030 with $14 \%$ EVs

In 2013, Madeira Island was provided with $25.9 \%$ of renewable energy sources. Reinforcing the power of the wind and photovoltaic energy in 2030, it will be possible to have $32.3 \%$ of energy from renewable sources. Even with these efforts, the importation of fossil fuels will increase in $9.7 \%$ and the emissions in $10.5 \%$; these figures would be even higher without the penetration of EVs, it's estimated $11.7 \%$ for importations and $10.8 \%$ for emissions.

In this case study, it must be considered that the EVs are charged with fuel-oil power plants. In fact the emissions are transferred from the tail pipes of ICEVs into the thermal power plants chimneys. The reductions in terms of primary energy consumption and global $\mathrm{CO}_{2}$ emissions are of little significance, and the reductions in gasoline and Diesel imports are substituted with fuel oil imports. The city of Funchal topology with a lot of hills and narrow streets that make ICEVs spend too much energy in their circulation, is responsible for a certain high level of pollution in the city. The EV adoption could bring mainly the advantage of decreasing the pollutant emissions in the city.

\section{Conclusions}

By analysing and comparing the islands in this study we can conclude that having a geothermal source of energy is extremely useful specially because it's constant and with a high load factor so that can provide the base load consumption. The Azores Islands have this advantage, specially Terceira Island that lays between two tectonic plates. The challenge here is to try to level the consumption profile in order to use this renewable power. EVs are one of the solutions, as they allow the geothermal penetration by increasing the off-peak demand and, at the same time reduce the energy dependency of the Island by reducing oil products imports.

As far as energy, economy and environment are concerned it's been verified that the more significant the penetration of EVs in the islands, the higher the benefits. These benefits are higher if the electricity generation mix includes a high percentage of renewable sources and consequently a low emissions' factor.

In these case studies it's perfectly understood that the transportation sector is an extremely significant consumer of energy, in such way that if the fleet was $100 \%$ electrical, the impacts to the network would cause difficulties to the operation system, and in a situation like that the best solution would be for the system's operator to have some control as far as the charge of the vehicles is concerned.

\section{Acknowledgement}

We would like to thank Engineer Alexandre Pereira, EDA (Azores Electricity) and Engineer Aires Henriques, EEM (Madeira network) for kindly making available all the data required to elaborate this article and, also, for the time they've spared in helping clarify all our questions.

\section{References}

[1] C. Furtado e T. Braga, "Energias Renováveis nos Açores," ARENA - Agência Regional da Energia e Ambiente da Região Autónoma dos Açores, 2007.

[2] N. Duic, M. Lerer e M. G. Carvalho, "INCREASING THE SUPPLY OF RENEWABLE ENERGY," International Journal of Sustainable, pp. 177-186, 4122003.

[3] J. Merino, C. Veganzones, J. A. Sanchez, S. Martinez e C. A. Platero, "Power System Stability of a Small Sized Isolated Network Supplied by a Combined Wind-Pumped Storage Generation System: A Case Study in the Canary Islands," energies, pp. 2351-2369, 52012.

[4] Azorina, "Plano de ação para a energia sustentável Arquipélago dos Açores," Março de 2012.

[5] R. Segurado, G. Krajacic, N. Duic e L. Alves, "Increasing the penetration of renewable energy resources in $S$. Vicente, Cape Verde," ELSEVIER, pp. 466-472, 672010.

[6] F. Chen, N. Duic, L. M. Alves e M. d. G. Carvalho, "Renewislands-Renewable energy solutions for islands," Renewable and Sustainable Energy Reviews, pp. 18881902, 2007.

[7] T. L. Jensen e Forum for Energy and Development, Renewable Energy on Small Islands. 2nd, 2000.

[8] N. Duic, G. Krajacic e M. d. G. Carvalho, "RenewIslands methodology for sustainable energy and resource planning for islands," Renewable \& Sustainable Energy Reviews, p. 1032-1062, 13102006.

[9] N. Duic e M. d. G. Carvalho, "Increasing renewable energy sources in island energy supply: case study Porto Santo," ELSEVIER, pp. 383-399, 2004.

[10] C. Camus e T. Farias, "The electric vehicles as a mean to reduce $\mathrm{CO} 2$ emissions and energy costs in isolated regions. The São Miguel (Azores) case study," Energy Policy 43, pp. 153 - 165, 2012. 